\title{
Low-Cost Cloud Enabled Wireless Monitoring System for Linear Fresnel Solar Plants ${ }^{\dagger}$
}

\author{
Rowida Meligy 1, Peio Lopez-Iturri 2,3, José Javier Astrain 3,4, Imanol Picallo 2, Hicham Klaina 5, \\ Mohamed Rady ${ }^{6}$, Filippo Paredes ${ }^{7}$, Fabio Montagnino ${ }^{7}$, Ana Vazquez Alejos ${ }^{5}$ and Francisco \\ Falcone ${ }^{2,3, *}$ \\ 1 Department of Mechatronics Engineering, Helwan University, Helwan 11795, Egypt \\ 2 Department of Electric, Electronic and Communication Engineering, Public University of Navarre, 31006 \\ Pamplona, Spain \\ 3 Institute of Smart Cities, Public University of Navarre, 31006 Pamplona, Spain \\ 4 Department of Statistics, Computer Science and Mathematics, Public University of Navarre, 31006 \\ Pamplona, Spain \\ 5 Department of Signal Theory and Communications, University of Vigo, 36310 Vigo, Spain \\ 6 Mechanical Engineering Department, Faculty of Engineering, King Abdulaziz University, Rabigh Campus, \\ Jeddah, Saudi Arabia \\ 7 Consorzio ARCA - Solar Living Lab, Viale delle Scienze Building 16, 90128 Palermo, Italy \\ * Correspondence: francisco.falcone@unavarra.es; Tel.: +34-948-169082 \\ + Presented at the 7th Electronic Conference on Sensors and Applications, 15-30 November 2020; Available \\ online: https://ecsa-7.sciforum.net/.
}

Published: 15 November 2020

\begin{abstract}
This paper presents the design of a cost-effective online wireless monitoring system of two Linear Fresnel solar plants (LFR) located in two different countries. The first LFR plant is installed in SEKEM medical center near Belbis city, Egypt, while the second one is installed in the campus of the University of Palermo, Italy. The proposed system is a standalone system that reduces the interaction of labors as it offers online wireless monitoring for important parameters of the LFR such as solar irradiance, ambient temperature, outlet and inlet collector temperature and heat transfer fluid flow. For that purpose, a Wireless Sensor Network (WSN) based on Arduino Mega boards coupled with XBee modules are used. The ZigBee XBee modules operate at $2.4 \mathrm{GHz}$, which have the advantages of being low cost and relatively low power consumption. The wireless nodes are supplied by solar paneled power banks, and send the data to a Cloud in order to monitor both LFR plants remotely. The proposed system has been implemented and tested successfully before the future deployment on the LFR plants.
\end{abstract}

Keywords: Linear Fresnel solar plant; wireless sensor networks; ZigBee; cloud; monitoring

\section{Introduction}

Renewable energy technologies have gained tremendous attention globally stimulated by the need of replacing the fossil energy systems, in spite of the fact that its availability varies across space and time. They are clean sources of energy derived from plentiful and unlimited sources that have a much lesser negative impact on environment than conventional fossil energy technologies. Several renewable energy sources exist that are in use such as hydropower, biomass, geothermal, solar energy and wind power [1]. Energy from the solar radiation has the largest potential for providing abundant, clean, safe, and reliable power.

There are several kinds of solar energy techniques that are currently available. The most common techniques are PhotoVoltaic cells/panels (PV) and Concentrated Solar Power (CSP). PVs are 
well-known electronic devices used to generate direct current electricity from solar radiation [1]. CSP systems are employed to reflect and concentrate sunlight onto receivers that collect solar energy and convert it into heat. Then it can be used to produce electricity via a steam turbine or a heat engine driving a generator. The CSP systems are advantageous over the PV technology by having higher conversion efficiencies, low investment cost, inherent thermal storage to work during the off hours [2]. There are four categories of CSP technologies that can be classified into line and punctual focus technologies according to the distribution of the focused solar radiation on a receiver [3]. Also, it can be classified into a single and two axes tracking technologies according to the sun tracking mechanism [4].

Monitoring and performance analysis of solar plants are crucial aspects to observe the stability and performance of the system. Monitoring plays an important role in decreasing the cost of operation and maintenance as well as ensuring faults detection and increasing the energy production efficiency [5,6]. Monitoring of the status of solar plants can be implemented either by using interface cables [7], wireless communications [8], or both [9]. Conventional wired monitoring system provides the security, speed and reliability for data transmission [10]. However, it suffers from technical limitations for its installation and the material cost is comparatively higher than using wireless monitoring systems. In addition to the costs of the wires, expenses for trenching, lightning protection, protection against rodents, and maintenances are also integrated [11]. The application of wireless communication technologies in PV plant and consequences of cost reduction make it an attractive technique for CSP plants [12]. Even so, there are no works in the literature reporting the application of Wireless Sensor Networks (WSN) to CSP plants, and specifically, no research has yet applied wireless communications to monitor the performance of Linear Fresnel Reflectors (LFR), which comprised on the category of the single axis tracking and line focus technologies.

This work proposes a low cost WSN-based monitoring system for LFR plants. The designed wireless nodes are based on ZigBee communication technology and are supplied by solar paneled power cells. The nodes are built on Arduino-compatible boards, and the employed sensors provide information regarding the efficiency, stability, fault detection, safety and security of the LFR plants. Also, in order to monitor remotely the LRF plants, the collected data is sent through a Gateway node to a specifically designed and developed Cloud and web-based monitoring system.

\section{Linear Fresnel Solar Plants}

LFR is a recent entrance technology of CSP based usually on small scale projects. It composes of many long rows segments of flat mirrors, which focus the light onto a fixed elevated tubular receiver running parallel to the reflector rotational axis. Segments are aligned horizontally and track the sun position such that the tubular receiver is illuminated (i.e. heated) without need to be moved. A second reflector can be installed on top of the receiver tube to enhance the captured sun light.

In a recent EU-funded project, Small scale Thermal Solar districts for Mediterranean communities (STS-MED), a solar multi-generation approach has been implemented in four different countries (Cyprus, Egypt, Jordan and Italy), each characterized by different collectors and different integration scenarios [13].

In this work we consider two LFR plants where PLC and SCADA systems are used for monitoring and control. The first one, installed in Egypt, includes LFR collectors (model IDEA 1FC1832) (see Figure 1) with a total area of $296 \mathrm{~m}^{2}$. It consists of a single Linear Fresnel solar collector, thermocline storage tank, $4 \mathrm{~kW}$ organic Rankine cycle (ORC), and $35 \mathrm{~kW}$ thermally driven chiller. The second plant, which includes the also LFR collector, has been commissioned in the campus of the University of Palermo, Italy (see Figure 2). It consists of three identical LFRs, thermocline ternary molten salt tank, $10 \mathrm{~kW}$ ORC, and $23 \mathrm{~kW}$ LiBr chiller. The plant has a total collector area of $480 \mathrm{~m}^{2}$. Specifications of both plants are given in Table 1.

The subsystems of multi-generation LFR plants that require adequate monitoring and control are, mainly, the sun tracking system, Thermal Energy Storage (TES) System, outlet temperature of HTF along the solar collector, power generation and cooling generation. 


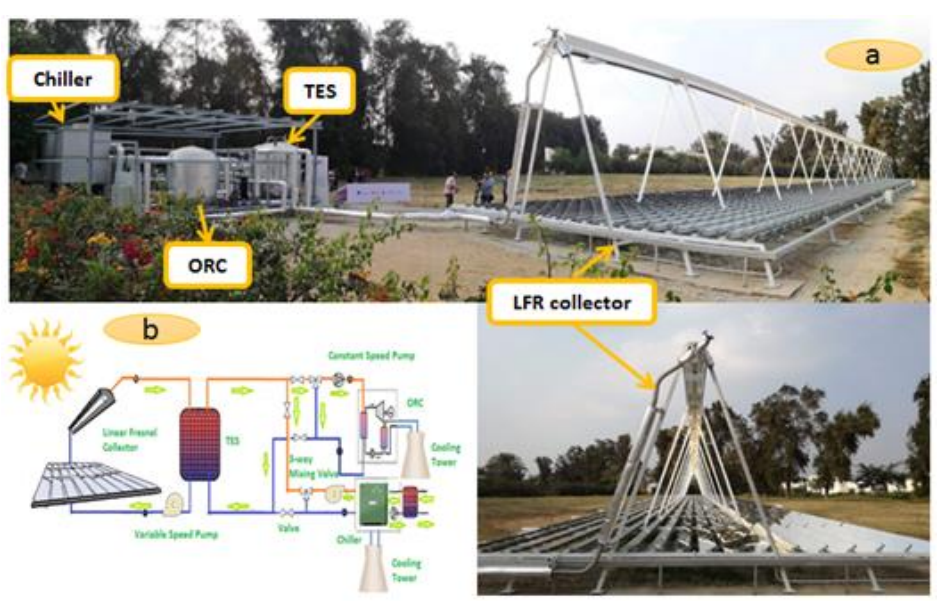

Figure 1. Sekem LFR solar plant, in Egypt.

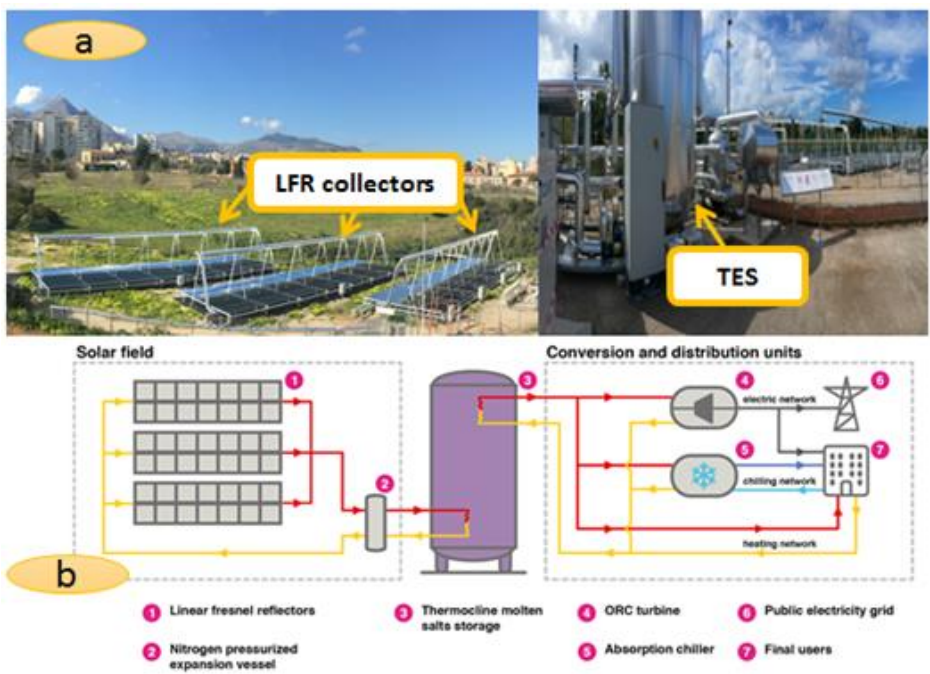

Figure 2. Palermo LFR solar plant, in Italy.

Table 1. Data specification of LFR plants.

\begin{tabular}{ccc}
\hline Data & LFR Egypt & LFR Italy \\
\hline Latitude & $30^{\circ} 25^{\prime} 05.5^{\prime \prime} \mathrm{N}$ & $38^{\circ} 06^{\prime} 01.0^{\prime \prime} \mathrm{N}$ \\
Longitude & $31^{\circ} 38^{\prime} 07.8^{\prime \prime} \mathrm{E}$ & $13^{\circ} 20^{\prime} 37.3^{\prime \prime} \mathrm{E}$ \\
Elevation & $35 \mathrm{~m}$ & $50 \mathrm{~m}$ \\
DNI per year & $1958 \mathrm{kWh} . \mathrm{m}^{-2}$ & $1703 \mathrm{kWh} . \mathrm{m}^{-2}$ \\
Aperture area & $299.50 \mathrm{~m}^{2}$ & $483.84 \mathrm{~m}^{2}$ \\
Thermal oil & Therminol 66 & Paratherm NF \\
Peak power & $115 \mathrm{~kW}$ & $190 \mathrm{~kW}$ \\
Receiver length & $52 \mathrm{~m}$ & $84 \mathrm{~m}$ \\
Working temperature & $140^{\circ} \mathrm{C}$ & $270{ }^{\circ} \mathrm{C}$ \\
\hline
\end{tabular}

\section{Monitoring System Architecture}

The proposed monitoring system of the LFR plants deployed in Egypt and Italy is presented in Figure 3. The WSN consists of many nodes distributed in different zones of the plant, creating a ZigBee network in a mesh topology. This topology will provide the full coverage of the area of interest as well as high degree of redundancy [14]. Figure 3 shows schematically the designed wireless monitoring system.

The ZigBee-based WSN nodes (see Figure 4a) will be deployed in each of the LFR plants. The collected data is sent to the wireless network coordinator (see Figure $4 b$ ), which will send the 
information to the Cloud via Ethernet connection, for its control and monitoring in the Public University of Navarre (UPNA), Spain (it could be also monitored from Egypt and Italy).
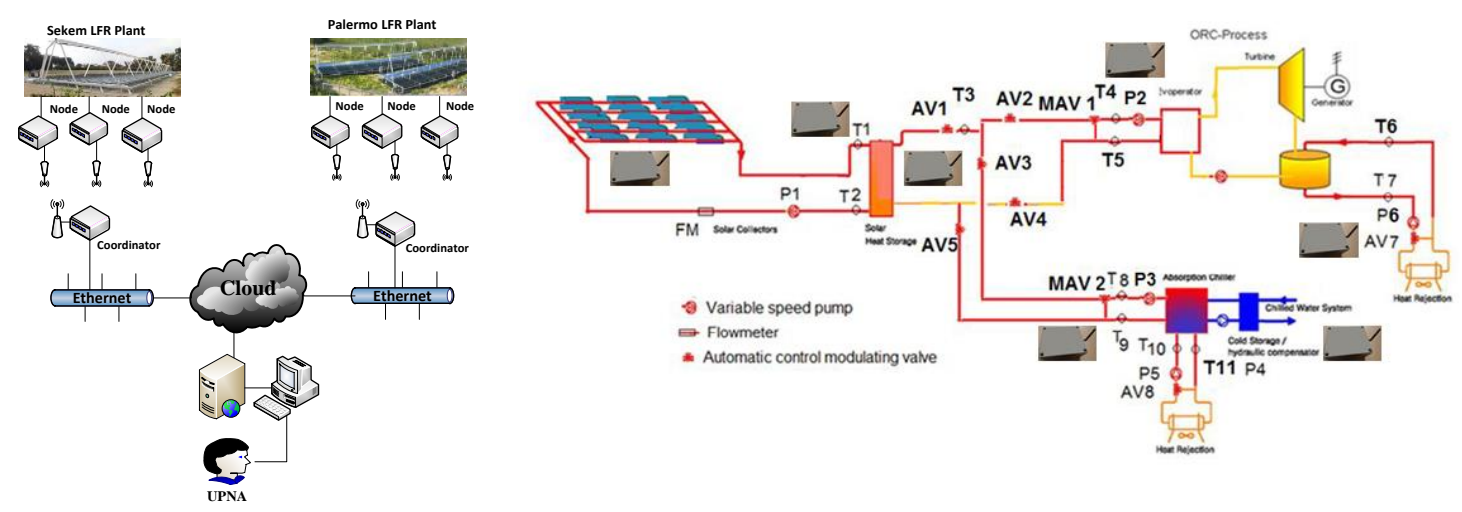

Figure 3. Communication architecture of the proposed monitoring system (left), and proposed WSN for the LFR plant monitoring system (right).

\subsection{Hardware}

This section gives the details on the different system components and sensors, and their implementation in the experimental setup. For the goal of monitoring fault detection, minimum time delay, safety and security, several low-cost sensors have been employed. All sensors are based on Arduino (or compatible boards) and the most relevant are shown in Figure 4a. Digi's XBee-PRO operating at $2.4 \mathrm{GHz}$ band have been employed as RF modules. The Arduino sensor shield allows the employed Arduino Mega boards to be integrated easily with sensors and XBee modules. The collected data by the network coordinator (see Figure $4 \mathrm{~b}$ ) is transferred to the Internet, and therefore to the Cloud, through an Ethernet shield.

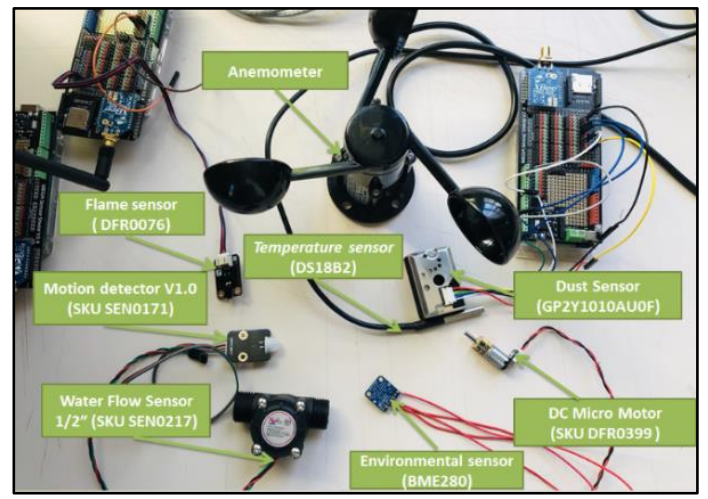

(a)

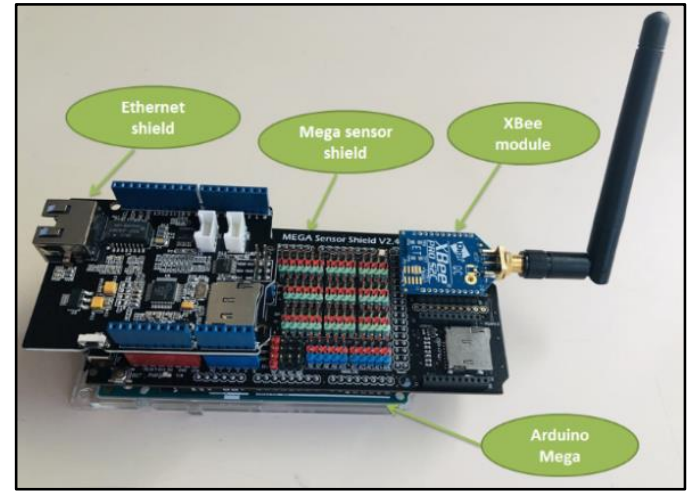

(b)

Figure 4. Employed hardware for the wireless ZigBee nodes: (a) Sensor nodes components; (b) Coordinator node.

Since the LFR plants are in construction when this study was carried out, a test-bed was proposed (prior a future deployment in the LRF plants) in order to assess the reliability and the performance of the designed WSN and the complete architecture of the monitoring system. For that purpose, wireless nodes (8 sensor nodes and 1 coordinator/gateway) were deployed within the UPNA campus, distributed in three different buildings and gardens. The duration of the tests was 3 hours, using different sampling intervals depending on the sensor type. The results showed that the $99.7 \%$ of the packets arrived successfully to the Cloud.

\subsection{Cloud-Based Monitoring}


Monitoring is performed with the aid of a cloud-based system. The usage of a cloud-based solution allows us to dispense with large and costly computing infrastructures, while offering an adequate scalability and adaptation to the specific computational needs. A specific cloud infrastructure has been developed, located at the campus of the Public University of Navarre. This infrastructure includes six TTL Teknoslim computers, equipped with Intel i5-7500 quad core processors, with 16 GB of RAM and two hard disks (a 256 GB SSD, and a 1TB HDD). The proposed monitoring system is based on well-known and -proven open-source tools, and includes the following components: an Apache NiFi component, in charge of data flow managing; an Apache Kafka component in charge of handling real-time data; a MySQL relational database; a MongoDB no relational database; and a Grafana platform for analytics and monitoring. Figure 5 (left) shows the components and flow of the cloud-monitoring system.
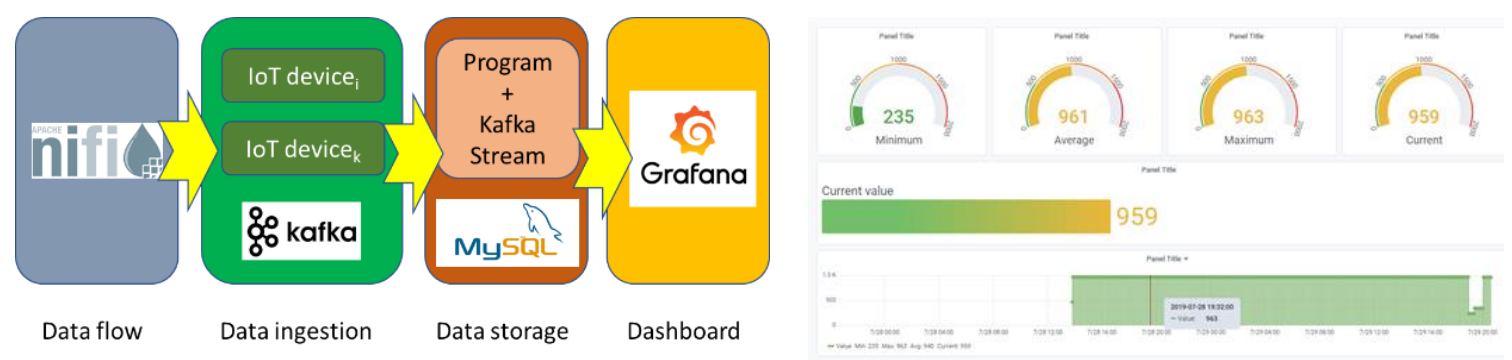

Figure 5. Components of the monitoring system and the graphic interface implemented in Grafana.

Finally, analytics and monitoring are then provided by a web-based Grafana platform, which collects the information from the MySQL database and provides structured and useful information over an interactive dashboard. The (web) access to this dashboard is restricted to users, since just authorized ones can either edit or view the dashboards. The frequency of information refresh can be configured according to the changing monitoring needs. Figure 5 (right) shows a screenshot of the monitoring system.

\section{Discussion}

This work proposed a wireless cloud-based monitoring system for LFR plants in order to facilitate remote monitoring and control. The monitored parameters are displayed on a web-based graphic interface for its analysis and processing. The WSN nodes are suited to measure various key parameters of LFR plants. The system can be configured with different sampling times and it is easily scalable to any number of measurement points, which renders it highly versatile. The test of the system has been successful, and the deployment on the real plants will be reported in future works.

Author Contributions: Conceptualization, F.F., A.A.; methodology, F.F., P.L.-I. and M.R.; software, R.M. and J.J.A.; validation, R.M., P.L.-I., I.P. and H.K.; formal analysis, R.M.; investigation, F.F., P.L.-I.; data curation, R.M.; writing-original draft, R.M., J.J.A.; writing-review and editing, P.L.-I.; visualization, R.M., I.P., H.K.; supervision, F.F. and M.R.; project administration, F.P., F.M., J.J.A.; funding acquisition, F.P., F.M. and F.F.

Funding: This research work was carried out within the framework of ENPI CBC Mediterranean Sea Basin Programme, 2007-2013. Project title: STS-Med "Small scale thermal solar district units for Mediterranean communities", Ref. I-A/2.3/174) co-funded by Electric System Research Program (RSE) of the Italian Minister of the Economic Development, Annual Research Plan 2015 (PAR2015); and the European Union's Horizon 2020 Research and Innovation program under grant agreement $N^{\circ} 774094$ (Stardust-Holistic and Integrated Urban Model for Smart Cities).

Conflicts of Interest: The authors declare no conflict of interest. The funders had no role in the design of the study; in the collection, analyses, or interpretation of data; in the writing of the manuscript, or in the decision to publish the results.

\section{References}

1. Alrikabi, N. Renewable Energy Types. J. Clean Energy Technol. 2014, 2, 61-64. 
2. Faraz, T. Benefits of Concentrating Solar Power over Solar Photovoltaic for power generation in Bangladesh. In Proceedings of the 2nd Intern. Conference on the Developments in Renewable Energy Technology (ICDRET), Dhaka, Bangladesh, 5-7 January 2012; IEEE: 2012; pp. 1-5.

3. Ahmadi, M.H.; Ghazvini, M.; Sadeghzadeh, M.; Alhuyi Nazari, M.; Kumar, R.; Naeimi, A.; Ming, T. Solar power technology for electricity generation: A critical Review. Energy Sci. Eng. 2018, 6, 340-361.

4. Mills, D. Advances in solar thermal electricity technology. Sol. Energy 2004, 76, 19-31.

5. Joshi, S.; Jadhav, A.; Gavate, N.; Yashwante, M. Wi-Fi Based Parameter Monitoring for Solar Plant. Int. J. Eng. Sci. Comput. 2016, 6, 4085-4087.

6. Nagalakshmi, R.; Babu, B.K.; Prashanth, D. Design and Development of a Remote Monitoring and Maintenance of Solar Plant Supervisory System. Int. J. Eng. Comput. Sci. 2014, 3, 9382-9385.

7. Purohit, N.L. Anshika, Data Acquisition of Solar Power Plant Using Scada System. Int. J. Eng. Trends Technol. 2015, 23, 189-194.

8. Vignesh, R.; Samydurai, A. Automatic Monitoring and Lifetime Detection of Solar Panels Using Internet of Things. Int. J. Innov. Res. Comput. Commun. Eng. 2017, 5, 7014-7020.

9. Zahran, M.; Atia, Y.; Alhosseen, A.; El-Sayed, I. Wired and Wireless Remote Control of PV System. WSEAS Trans. Syst. Control 2010, 5, 656-666.

10. Shukla, S.; Meghana, K.M.; Manjunath, C.R.; et al. Comparison of Wireless Network over Wired Network and Its Type. Int. J. Res. GRANTHAALAYAH 2017, 5, 14-20.

11. Pfahl, A.; Randt, M.; Meier, F.; Zaschke, M.; Geurts, C.P.; Buselmeier, M. A Holistic Approach for Low Cost Heliostat Fields, International Conference on Concentrating Solar Power and Chemical Energy Systems, SolarPACES 2014, Beijing, China. Energy Procedia 2015, 69, 178-187.

12. Dieckmann, S.; Dersch, J.; Giuliano, S.; Puppe, M.; Lüpfert, E.; Hennecke, K.; Pitz-Paal, R.; Taylor, M.; Ralon, P. LCOE reduction potential of parabolic trough and solar tower CSP technology until 2025. In Proceedings of the AIP Conference Proceedings, Abu Dhabi, UAE, 11-14 October 2016; Volume 1850, pp. 160004-1160004-8.

13. Montenon, F.P.; Giaconia, A.; Fylaktos, N.; Di Bono, S.; Papanicolas, C.N.; Montagnino, F.M. Solar MultiGeneration in The Mediterranean Area, The experience of the STS-MED project. In Proceedings of the 11th ISES EuroSun Conference, La Palma de Mallorca, Spain, 11-14 October 2016.

14. Katsioulis, V. Design of a Wireless Monitoring System Based on the ZigBee Protocol for Photovoltaic Systems. Ph.D. Thesis, Brunel University, England, UK, 2011.

(C) 2020 by the authors. Submitted for possible open access publication under the terms and conditions of the Creative Commons Attribution (CC BY) license (http://creativecommons.org/licenses/by/4.0/). 